\title{
Optimization of the electrostatic fumigation process of grain seeds in a transferled layer
}

\author{
Sergey Shubkin ${ }^{1}$, Sergey Buneev ${ }^{1}$, Evgeny Slivinsky ${ }^{1}$, Sergey Radin $^{1 *}$, and Sergey \\ Yeletskikh $^{1}$ \\ ${ }^{1}$ Bunin Yelets State University, Kommunarov str., 28, the Lipetsk region, 399770, Russia
}

\begin{abstract}
The article presents the results of studies of the process of electrostatic fumigation of seeds of leguminous crops with an ionized fumigating agent in a drum-type installation by methods of mathematical planning. A complete factorial experiment of type 23 is implemented. An equation is obtained that adequately describes this process, and its graphic interpretation is given. Practical recommendations are given for the development of regimes for industrial fumigation of seeds of leguminous crops, allowing to predict the conditions of the process.
\end{abstract}

\section{Introduction}

Traditionally, fumigation has been widely used to prevent the introduction and spread of regulated pests and therefore has a positive impact on biodiversity [1,2]. The purpose of fumigation as a phytosanitary measure is to ensure the mortality of pests with a given efficiency [3].

Fumigation should ensure the achievement of the required level of critical parameters (concentration or dose, temperature, duration) in the entire mass of the product, which allows to achieve the declared efficiency [4].

Factors such as humidity, pressure, and changes in the composition of the gas environment created by the package or product can affect the effectiveness of fumigation [5]. Other factors that must be taken into account during fumigation include the depth of penetration of the fumigant, the sorption of the fumigant by the package or product, the specific gravity of the fumigant, and the circulation of the fumigant [6].

Currently, the process of fumigation of seeds of leguminous crops is carried out in conditions of silage and floor storage [7]. Carrying out the process under such conditions does not fully ensure the distribution of the active components of the fumigant throughout the entire volume of the product [8]. To increase the efficiency of the process, it is advisable to use the constant stirring mode [9].

The existing trends in the development of technology for fumigation of seeds of leguminous crops are associated with the creation of new fumigation equipment [10]. One of such directions of increasing the efficiency of installations for ensuring phytosanitary treatment of seeds of leguminous crops is the use of electrostatic elements, which makes it

*Correcting author: radin81@mail.ru 
possible to have an additional detrimental effect on pathogenic microflora, quarantine insect pests [11].

The purpose of the study is the determination of the optimal modes of electrostatic fumigation of seeds of leguminous crops with an ionized fumigating agent in a drum-type installation by constructing a polynomial regression model of the second order that adequately describes this process.

\section{Research methods}

The research was carried out on the basis of the Agroindustrial Institute of YSU named after I.A. Bunin in research laboratories for the study of processes and devices for food production, as well as electro-physical methods of processing food environments. In order to reduce the volume of experimental studies and optimize the modes of electro-static fumigation of seeds of leguminous crops with an ionized fumigating agent in the pouring layer, the methods of regression analysis were used, namely, mathematical planning of the full factorial [12].

Pea seeds were chosen as a model object of research.

To carry out research and study the process of electrostatic fumigation of pea seeds in an electrostatic field in an overflowing layer, an experimental setup was used, the prospects of which are described in [13]. The schematic diagram of the experimental setup is shown in Fig. 1.

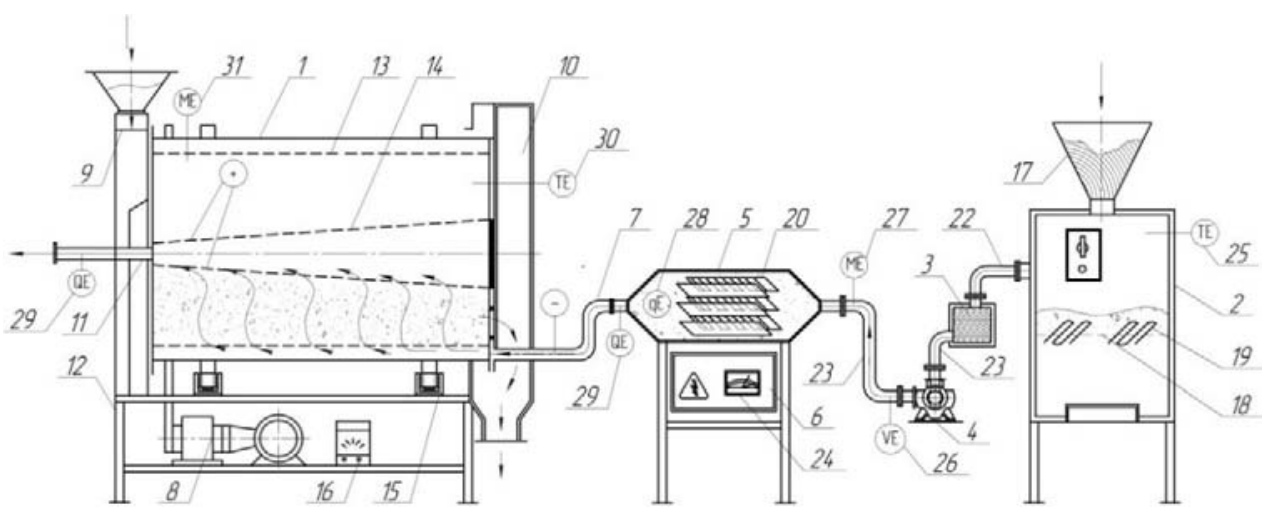

Fig. 1. Schematic diagram of the experimental setup: 1 - fumigation chamber; 2 - generator of fumigating agent; 3 - filter; 4 - pump; 5 - ionizer; 6 - high-voltage generator; 7 - collector; 8 - drive; 9 boot device; 10 - unloading device; 11 - outlet device; 12 - steel frame; 13 - channel nozzles; 14 perforated conical pipe; 15 - support roller; 16 - frequency converter; 17 - loading branch pipe; 18 sheet; 19 - thermoelement; 20 - corona electrodes; 21, 22, 23 - pipelines; 24 - multimeter; 25 - thermoelectric converter; 26 - semiconductor hot-wire anemometer; 27 -hygrometer; 28 - meter of the strength of the electrostatic field, 29 - concentration sensor; 30 - resistance thermocouple; 31 - moisture meter.

When conducting research, the installation allows you to maintain the following basic parameters of the technological process of electrostatic fumigation: temperature range in the generator of the fumigating agent $303 \ldots 373 \mathrm{~K}$, the intensity of the electrostatic field 35 ... $95 \mathrm{kV} / \mathrm{m}$; frequency of rotation of the fumigation chamber $1.5 \ldots 15 \mathrm{~min}^{-1}$; temperature of the fumigant mixture $291 \ldots 320 \mathrm{~K}$; fumigation rate $0,15 \ldots 1,6 \mathrm{~m} / \mathrm{s}$; relative humidity of the fumigant mixture $50 \ldots 90 \%$.

The fumigating agent was used in the form of a powder, which gives off gases during its thermal decomposition [14]. 
The efficiency of the electrostatic fumigation process is characterized by the degree of deposition of the fumigant on pea seeds K, which can be determined using expression (1), which expresses the ratio of the difference in the concentration of the fumigant at the input $c_{1}$ and output $c_{2}$ fumigation chamber to concentration at the entrance to the fumigation chamber $c_{1}$ :

$$
K=\frac{c_{1}-c_{2}}{c_{1}},
$$

where $c_{1}-$ concentration of fumigant at the entrance to the fumigation chamber;

$c_{2}$ - concentration of fumigant at the outlet of the fumigation chamber.

It is of interest to clarify the nature of the dependences under consideration. For this purpose, a series of experiments was carried out in an experimental setup.

To simulate and optimize the rational modes of electrostatic fumigation of pea seeds with an ionized fumigating agent in the overflowing layer, Box-Wilson compositional plans were used, which make it possible to construct a second-order polynomial model describing the response dependence $Y$ from factors $x_{j}$. For the convenience of calculations, all calculations were performed in the system of symbolic mathematics Mathcad.

\section{Results of the study}

As is known, the mathematical planning of a full factorial experiment is based on experimental and statistical methods that involve several positions.

First of all, it is necessary to construct an adequate regression model, which would describe the dependence of the output values of the parameters on the factors selected for the study, rather accurately.

With the help of mathematical methods of experimental design, such a study was carried out for several factors (will be indicated below) that have a direct impact on what happens in the installation for electrostatic fumigation. [15].

In this case, the model of the process under study can be described by a polynomial of the second degree, which analytically can be represented in the form:

$$
y=b_{0}+\sum_{i=1}^{N} b_{i} x_{i}+\sum_{i=1}^{N} b_{i i} x_{i}^{2}+\sum_{i \leq j}^{N} b_{i j} x_{i} x_{j},
$$

where $b_{0}$ - coefficient at the zero degree of the variable, which is given by finding the mean value of the response, with the condition that the factors under study are located at zero levels; $x$ - variable values of the factors that determine the response function, $i, j$ - factor indices; $b_{i}$ - coefficients at the first degree of the variable, $b_{i j}$ - coefficients of pair interaction (these coefficients indicate how the degree of influence of one factor changes when another is varied), - the number of factors under consideration contained in the planning matrix.

In order to reduce and reduce the cost of setting up and conducting the experimental part of the research, it is advisable to implement a full factorial experiment of the type $2^{3}$ with the corresponding planning matrix.

As you know, the total number of experiments with factors is determined by the ratio: 


$$
n=2^{m}+2 m+n_{0}
$$

where $n_{0}$ - the number of experiments in the center of the plan, which in our case is 6 . 20.

Thus, in the case of a full factorial experiment (), the total number of experiments was

As the main factors influencing and characterizing the process of electrostatic fumigation of pea seeds with an ionized fumigating agent in the pouring layer, the parameters of the environment inside the fumigation chamber were selected:

1) $x_{1}$ - rotation frequency of the fumigation chamber, $\mathrm{min}^{-1}$;

2) $x_{2}$ - voltage across corona electrodes, $\mathrm{kV}$;

3) $x_{3}$ - temperature, $K$.

Table 1 shows the characteristics of planning.

Table 1. Characteristics of planning.

\begin{tabular}{|c|c|c|c|}
\hline \multirow{2}{*}{ Planning conditions } & \multicolumn{3}{|c|}{ Factor values } \\
\cline { 2 - 4 } & $x_{1}, \mathrm{~min}^{-1}$ & $x_{2}, k V$ & $x_{3}, K$ \\
\hline Main level (0) & 5 & 30 & 300 \\
\hline Variation interval & 0,5 & 5 & 3 \\
\hline Upper level (+1) & 8 & 40 & 311 \\
\hline Lower level (-1) & 1 & 20 & 291 \\
\hline Upper "star" point (+1,682) & 5,841 & 38,41 & 305,046 \\
\hline Lower "star" point (-1,682) & 4,159 & 21,59 & 294,954 \\
\hline
\end{tabular}

The output parameters are indicators:

1) $Y_{1}$ - fumigant content on pea seeds after the electrostatic fumigation process, $\mathrm{mg} / \mathrm{kg}$;

2) $Y_{2}$ - specific energy costs per $1 \mathrm{~kg}$ of finished product, which determine the energy consumption of the process and are one of the most important indicators of its energy efficiency, $\mathrm{kJ} / \mathrm{kg}$.

Statistical processing of the obtained experimental data made it possible to obtain analytical dependences describing the studied process of electrostatic fumigation of pea seeds in the following form:

$$
\begin{gathered}
Y_{1}=31,16+6,69 X_{1}+5,48 X_{2}+7,49 X_{1}^{2}-5,42 X_{2}^{2}-5,41 X_{3}^{2}+ \\
+0,362 X_{1} X_{3}+0,412 X_{2} X_{3} ; \\
Y_{2}=0,839+0,311 X_{1}+0,17 X_{2}+0,17 X_{3}+0,288 X_{1}^{2}-0,118 X_{2}^{2}, \\
-0,118 X_{3}^{2}-0,025 X_{1} X_{2}-0,025 X_{1} X_{3}-0,018 X_{2} X_{3} ;
\end{gathered}
$$

where $X_{i}$ - coded values of factors that are associated with true values in the following form:

$$
X_{1}=2\left(x_{1}-8\right), X_{2}=\frac{x_{2}-40}{5}, X_{3}=\frac{x_{3}-311}{3} \text {. }
$$


Further, considering the obtained regression equations (4) and (5), it is easy to see which of the factors affect the studied process of electrostatic fumigation of pea seeds to a greater extent

Thus, the fumigant content on pea seeds is largely influenced by the rotational speed of the drum-type fumigant chamber. To a lesser extent, the voltage on the corona electrodes and the temperature. The specific energy consumption per $1 \mathrm{~kg}$ of finished product after electrostatic fumigation is largely influenced by the rotational speed of the drum-type fumigation chamber. The least significant effect is temperature. A graphical interpretation of the dependence of the amount of fumigant on pea seeds $Y_{1}(\mathrm{mg} / \mathrm{kg})$ on the factors studied is shown in Fig. 2-4.

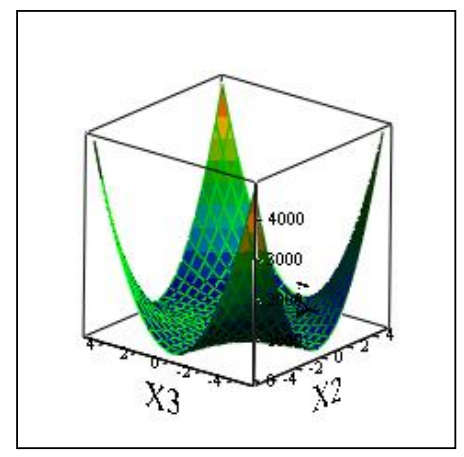

a)

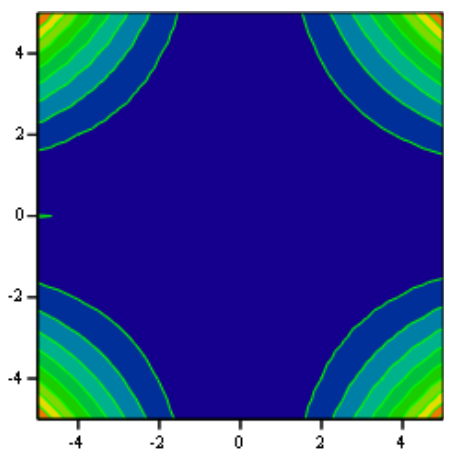

b)

Fig. 2. Graphs of dependence of the amount of fumigant on pea seeds. $Y_{I}(\mathrm{mg} / \mathrm{kg})$ from the factors studied (at $X_{I}=0$ ): a) - response surface; b) - two-dimensional section of the response surface.

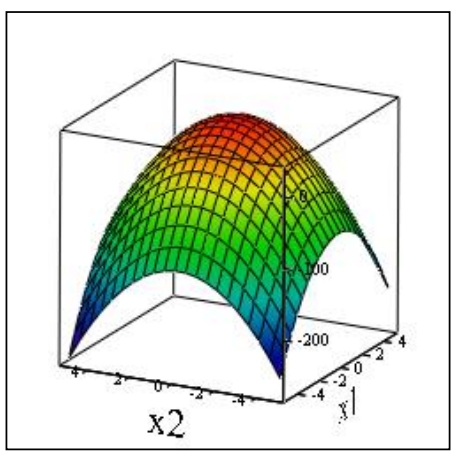

a)

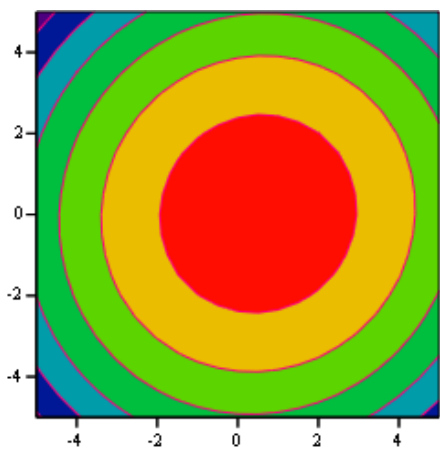

b)

Fig. 3. Graphs of dependence of the amount of fumigant on pea seeds. $Y_{I}(\mathrm{mg} / \mathrm{kg})$ from the factors studied (at $X_{2}=0$ ): a) - response surface; b) - two-dimensional section of the response surface. 


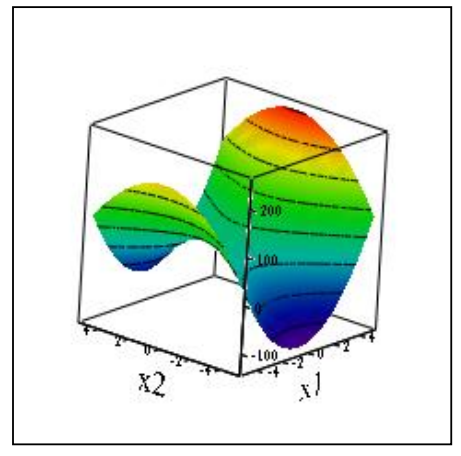

a)

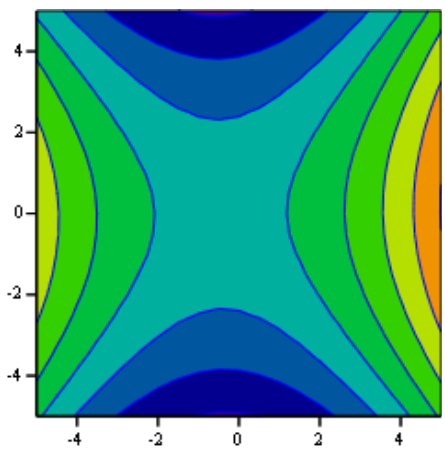

b)

Fig. 4. Graphs of dependence of the amount of fumigant on pea seeds. $Y_{I}(\mathrm{mg} / \mathrm{kg})$ from the factors studied (at $X_{3}=0$ ): a) - response surface; b) - two-dimensional section of the response surface.

Based on the fact that we are dealing with two indicators of quality $Y_{l}$ and $Y_{2}$, we will consider the first of them as the main one, and the second as a limitation.

To find the operating modes of the drum-type fumigation chamber, an optimization problem was formulated: it is necessary to find such values of the variables $X_{1}, X_{2}, X_{3}$, which would ensure the optimal content of fumigant on the pea seeds after the electrostatic fumigation process $y_{1}=f\left(X_{1}, X_{2}, X_{3}\right)$ at a given value of specific energy costs $y_{2}=\varphi_{1}\left(X_{1}, X_{2}, X_{3}\right)$. Analytically, this is expressed by the following relation:

$$
\varphi_{2}\left(X_{1}, X_{2}, X_{3}\right)=X_{1}^{2}+X_{2}^{2}+X_{3}=R^{2}
$$

That is, we have a sphere of radius $R$, the center of which coincides with the center of the experiment.

The problem described above was solved using the method of indefinite Lagrange multipliers using the symbolic mathematics package Mathcad [15].

To check the reliability of the results obtained, an appropriate number of parallel experiments were carried out. The data obtained were within the calculated confidence intervals for all selected criteria. In this case, the root-mean-square error did not exceed $4.6 \%$.

The following should be taken as suboptimal intervals for changing the parameters: rotation frequency of the fumigation chamber $4.5 \ldots 5.5 \mathrm{~min}^{-1}$, tension on corona electrodes $20 \ldots 40 \mathrm{kV}$ and temperature $305 \ldots 310 \mathrm{~K}$.

\section{Conclusion}

As a result of mathematical modeling of electrostatic fumigation of pea seeds in an overflowing layer, nonlinear equations (4) and (5) were obtained, which adequately describe the process under consideration, and its graphic interpretation is given.

The use of experimental-statistical methods for planning the experiment made it possible to draw appropriate conclusions about the influence of the factors under study.

Analytical dependencies have been obtained, which constitute a mathematical model of the process under study, with the help of which it is possible to calculate the degree of deposition of the fumigant on pea seeds.

Thus, summing up the research carried out, we can draw the following conclusion: the course of the process of electrostatic fumigation of seeds of leguminous crops in the over- 
flowing layer has a complex character; the frequency of rotation of the fumigation chamber has a significant effect on the course of the process, on which the uniformity of the distribution of the fumigating component throughout the volume of the product depends.

The results of the solved optimization problem made it possible to identify a rational range of changes in the input factors according to three investigated criteria for the functioning of the fumigation plant. The obtained mathematical model can be used to create fumigation installations, as well as a method for controlling technological modes of fumigation of seeds of leguminous crops.

\section{References}

1. M. Akhlaq, S. W. Ali, Cereal Chemistry, 97(4), 849-858 (2020), doi: 10.1002/cche. 10307.

2. F. H. Arthur, Journal of Pest Science, 85(3), 323-329 (2012), doi: 10.1007/s10340-0120439-9.

3. F. H. Arthur, J. F. Campbell, M. D. Toews, Journal of Stored Products Research, 53, 714 (2013), doi: 10.1016/j.jspr.2012.12.008.

4. R. Aulicky, V. Stejskal, G. S. Opit, Pakistan Journal of Zoology, 51(2), 475-782 (2019), doi: 10.17582/journal.pjz/2019.51.2.475.482.

5. Y. Bai, J. Wang, J. Jiao, Sustainable Production and Consumption, 27, 471-484 (2021), doi:10.1016/j.spc.2021.01.014.

6. P. C. Coradi, I. T. P. Dubal, N. D. S. Bilhalva, et al., Journal of Food Processing and Preservation, 44(12) (2020), doi: 10.1111/jfpp.14961.

7. P. Igboji, N. Okey, A. Udeh, International Journal of Agricultural Resources, Governance and Ecology, 14(1), 91-103 (2018), doi: 10.1504/IJARGE.2018.090855.

8. D. Röske, Acta Imeko, 9(5), 407-413 (2021), doi:10.21014/ACTA_IMEKO.V9I5.1010.

9. N. Manu, E. A. Osekre, G. P. Opit, et al., Journal of Stored Products Research, 76, 102-110 (2018), doi: 10.1016/j.jspr.2018.01.001.

10. A. Paul, M. Radhakrishnan, S. Anandakumar, et al., Comprehensive Reviews in Food Science and Food Safety, 19(3), 1125-1155 (2020), doi: 10.1111/1541-4337.12555.

11. S. Shubkin, S. Buneev, S. Radin, IOP Conference Series: Materials Science and Engineering, 1001(1) (2020), doi:10.1088/1757-899X/1001/1/012128.

12. S. Rajendran, K. R. Nayak, S. S. Anjum, Pest Management Science, 57(5), 422-426, doi: $10.1002 /$ ps.283.

13. K. Tan, S. K. Obendorf, Journal of Membrane Science, 305(1-2), 287-298 (2007), doi: 10.1016/j.memsci.2007.08.015.

14. M. D. Toews, F. H. Arthur, J. F. Campbell, Environmental Entomology, 34(1), 164169, doi: 10.1603/0046-225X-34.1.164.

15. J. Zhu, C. Wen, J., Zhu, H. Zhang, X. Wang, National Academy of Sciences of the United States of America, 117(52), 33117-33123 (2021), doi: 10.1073/PNAS.2014241117. 